\title{
One-Pot Synthesis of Optically Active Poly(3-buten-2-ol) from Methyl Vinyl Ketone
}

\author{
Toshio MASUDA and Hiroshi IBUKI \\ Department of Polymer Chemistry, Kyoto University, \\ Sakyo-ku, Kyoto 606, Japan.
}

(Received November 12, 1979)

\begin{abstract}
KEY WORDS One-Pot Synthesis / Optically Active Polymer / Methyl Vinyl
Ketone / Poly(3-buten-2-ol) /
\end{abstract}

Two methods are available for the synthesis of optically active poly(3-buten-2-ol) from poly(methyl vinyl ketone): (i) rhodium-chiral ligands catalyzed hydrosilylation followed by hydrolysis, ${ }^{1}$ and (ii) reduction with lithium aluminum hydride modified with chiral compounds. ${ }^{2}$ Higher optical rotations are attained by the former reaction.

Poly(methyl vinyl ketone) is, however, considerably difficult to handle since it is in the form of a hard lump and sensitive to light. Therefore, if possible, the direct synthesis of poly(3-buten-2-ol) from methyl vinyl ketone will be very convenient.

This paper describes an easy method for synthesizing optically active poly(3-buten-2-ol), by carrying out both the polymerization of methyl vinyl ketone and the subsequent hydrosilylation of the polymer in one pot.

\section{EXPERIMENTAL}

A typical procedure for the one-pot synthesis of poly(3-buten-2-ol) is as follows: Reactions were carried out in a $50 \mathrm{ml}$ flask equipped with a three-way stopcock under a dry nitrogen atmosphere. Methyl vinyl ketone $(2.10 \mathrm{~g}, 30 \mathrm{mmol})$ was polymerized by azobisisobutyronitrile (AIBN) $(49.3 \mathrm{mg}, 0.30 \mathrm{mmol})$ in tetrahydrofuran (THF) $(7.57 \mathrm{ml})$ at $60^{\circ} \mathrm{C}$ for $24 \mathrm{~h}$ (reaction mixture, $10 \mathrm{ml}$ ). To the polymer solution formed were added THF $(3.92 \mathrm{ml})$ and diphenylsilane $(6.08 \mathrm{~g}, 33 \mathrm{mmol})$ (reaction mixture, $20 \mathrm{ml})$. In a separate flask were mixed $\mu$-dichlorotetracyclooctenedirhodium $(53.8 \mathrm{mg}, 0.075 \mathrm{mmol})$, (-)-2,3-O-isopropylidene-2,3-dihydroxy-1,4-bis- (diphenylphosphino)butane (( -)-DIOP; optical purity $>98 \%, 78.5 \mathrm{mg}, 0.158 \mathrm{mmol})$ and THF $(10 \mathrm{ml})$. After this mixture aged for $30 \mathrm{~min}$ at $50^{\circ} \mathrm{C}$, it was added to the polymer solution at $50^{\circ} \mathrm{C}$ (reaction mixture, $30 \mathrm{ml}$ ). Hydrosilylation was continued for $48 \mathrm{~h}$. Then $1 N$ hydrochloric acid $(5 \mathrm{ml})$ was added and the mixture was stirred for $1 \mathrm{~h}$ at room temperature. It was neutralized with $1 N$ aqueous ammonia. Following evaporation of the volatile materials, the residue was dissolved in THF, and the insoluble salt was filtered off. The polymer formed was precipitated in a mixture of ether and $n$-hexane (volume ratio, $4: 1)$. The crude polymer was purified by reprecipitation. The overall yield, $75 \%$; conversion of $\mathrm{C}=\mathrm{O}$ to $\mathrm{CHOH}, 100 \% ;{ }^{1} \mathrm{H}$ NMR $\left[\left(\mathrm{CD}_{3}\right)_{2} \mathrm{SO}\right]$ $\delta 4.4-3.5$ (br, HC-O); $3.3(\mathrm{~s}, \mathrm{OH}), 2.2-0.0(\mathrm{br}$, $\left.\mathrm{CH}_{2} \mathrm{CH}, \mathrm{CH}_{3}\right)$; IR $3400(\mathrm{OH}), 2975$ and $2925(\mathrm{CH})$, $1050(\mathrm{C}-\mathrm{O}) \mathrm{cm}^{-1}$.

\section{RESULTS AND DISCUSSION}

The process of the one-pot synthesis is shown in Scheme I. In order to achieve this, it is necessary for

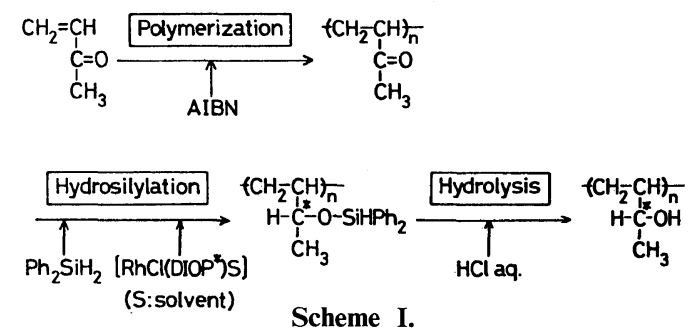


Table I. One-pot synthesis of poly(3-buten-2-ol) ${ }^{\mathrm{a}}$

\begin{tabular}{|c|c|c|c|c|c|c|}
\hline \multirow[b]{2}{*}{ Solvent } & \multirow{2}{*}{$\frac{\text { Temp }}{{ }^{\circ} \mathrm{C}}$} & \multirow{2}{*}{$\frac{\text { Time }}{\text { day }}$} & \multicolumn{2}{|c|}{ Conversion $/ \%$ b } & \multicolumn{2}{|c|}{$[\alpha]_{D} /{ }^{\circ c}$} \\
\hline & & & $\begin{array}{l}\text { Polymer } \\
\text { isolated }\end{array}$ & $\begin{array}{l}\text { One-pot } \\
\text { synthesis }\end{array}$ & $\begin{array}{l}\text { Polymer } \\
\text { isolated }\end{array}$ & $\begin{array}{l}\text { One-pot } \\
\text { synthesis }\end{array}$ \\
\hline THF & 0 & 14.0 & 100 & 99 & 37.1 & 39.9 \\
\hline THF & 50 & 2.0 & 99 & 99 & 27.3 & 29.0 \\
\hline$p-\mathrm{DOX}^{\mathrm{d}}$ & 50 & 2.0 & 100 & 99 & 25.0 & 28.9 \\
\hline
\end{tabular}

a Polymerization: $[\mathrm{M}]_{0}=3.0 \mathrm{mol1}{ }^{-1} ; \quad[\mathrm{M}]_{0} /[\mathrm{C}]=100 ; \quad 60^{\circ} \mathrm{C} ; \quad 24 \mathrm{~h} . \quad$ Hydrosilylation: $[\mathrm{C}=\mathrm{O}]=1.0 \mathrm{mol1} 1^{-1}$; $[\mathrm{C}=\mathrm{O}] /[\mathrm{Rh}]=200$.

b Conversion for hydrosilylation.

c $c=1.0 \mathrm{~g} \mathrm{dl}^{-1}$, in $\mathrm{C}_{2} \mathrm{H}_{5} \mathrm{OH}$.

d $p$-DOX, $p$-dioxane.

the solvent of the second reaction to be the same as or contain the solvent of the first reaction. Table I shows the results for the synthesis of optically active poly(3-buten-2-ol) in THF and $p$-dioxane ( $p$-DOX) as solvents. It was confirmed separately that the conversion in polymerization reached $100 \%$ under the conditions shown in Table I. The conversion in hydrosilylation also reached about $100 \%$ both in the one-pot synthesis and in the reaction with poly(methyl vinyl ketone) isolated. The former method always gave products having larger optical rotations than the latter. This suggests that the reaction system with the polymer isolated contains more impurities. Thus the one-pot synthesis is not only easy to perform but is also favorable for obtaining a product with larger optical rotation. The optical rotation of products increased with decreasing reaction temperature for both methods, though it hardly depended on whether the solvent was THF or $p$-DOX. The values of optical rotation were reproducible to about $\pm 5 \%$ for duplicate runs of the reaction.

Benzene has been used exclusively so far as a solvent in the hydrosilylation of low-molecularweight ketones, and the solvent effect on the optical rotation of product is not known. ${ }^{3}$ Benzene is, however, a nonsolvent of poly(methyl vinyl ketone), and thus cannot be used in the present reaction.

To clarify whether THF and $p$-DOX are optimal solvents for the present one-pot synthesis, hydrosilylation was performed in various solvents, using poly(methyl vinyl ketone) isolated. As is clear from Table II, THF and $p$-DOX gave products having the largest optical rotations among the solvents examined. THF and $p$-DOX are also proper solvents for the polymerization of methyl vinyl ketone.
Table II. Asymmetric reduction of poly(methyl vinyl ketone) via hydrosilylation ${ }^{\mathrm{a}}$

\begin{tabular}{|c|c|c|c|c|}
\hline \multirow{2}{*}{ Solvent } & Temp & Time & Conversion & {$[\alpha]_{\mathrm{D}}{ }^{\mathrm{c}}$} \\
\hline & ${ }^{\circ} \mathrm{C}$ & day & $\%$ & $\circ$ \\
\hline $\mathrm{THF}$ & 50 & 2.0 & 99 & 27.3 \\
\hline$p$-DOX & 50 & 2.0 & 100 & 25.0 \\
\hline $\mathrm{C}_{6} \mathrm{H}_{5} \mathrm{OCH}_{3}$ & 50 & 2.0 & 100 & 12.9 \\
\hline$\left(\mathrm{CH}_{3} \mathrm{OCH}_{2}\right)_{2}$ & 50 & 2.0 & 100 & 7.5 \\
\hline$\left(\mathrm{CH}_{2} \mathrm{Cl}\right)_{2}$ & 50 & 2.0 & 100 & 11.8 \\
\hline $\mathrm{C}_{6} \mathrm{H}_{5} \mathrm{Cl}$ & 60 & 2.0 & 100 & 5.5 \\
\hline $\mathrm{CH}_{3} \mathrm{CN}$ & 50 & 7.0 & 44 & - \\
\hline $\mathrm{C}_{6} \mathrm{H}_{5} \mathrm{NO}_{2}$ & 50 & 2.0 & 40 & - \\
\hline
\end{tabular}

${ }^{a}[\mathrm{C}=\mathrm{O}]=1.0 \mathrm{moll}^{-1} ;[\mathrm{C}=\mathrm{O}] /[\mathrm{Rh}]=100$.

b Conversion of $\mathrm{C}=\mathrm{O}$ to $\mathrm{CHOH}$.

c $c=1.0 \mathrm{~g} \mathrm{dl}^{-1}$, in $\mathrm{C}_{2} \mathrm{H}_{5} \mathrm{OH}$.

Therefore, it is concluded that these solvents are the most suitable for the present one-pot synthesis.

Acknowledgment. The authors wish to thank Professor T. Higashimura for his valuable suggestions and encouragements. This work was partly supported by a Grant-in-Aid for Scientific Research from the Ministry of Education, Science and Culture (No. 465300).

\section{REFERENCES}

1. T. Masuda and J. K. Stille, J. Am. Chem. Soc., 100, 268 (1978).

2. Y. Minoura and H. Yamaguchi, J. Polym. Sci., A-1, 6, 2013 (1968).

3. I. Ojima, K. Yamamoto, and M. Kumada, "Aspects of Homogeneous Catalysis,” Vol. 3, R. Ugo, Ed., D. Reidel Publishers Co., Donarecht-Holland, 1977. 